\title{
Research on Integrated Development of Ili Accordion Culture and Tourism*
}

\author{
Yan Li \\ Faculty of Biology and Geography \\ Yili Normal University \\ Yining, China \\ Tingyu Shi \\ Faculty of Biology and Geography \\ Yili Normal University \\ Yining, China \\ Youwen Wang \\ Faculty of Marxism \\ Yili Normal University \\ Yining, China
}

\begin{abstract}
Ili, Xinjiang, is a large opening and core pivot of "the Silk Road Economic Belt and the 21st-Century Maritime Silk Road" ("the Belt and Road") opening to the West of China. Yining, the capital city, is the most western border city and state-level excellent tourist city and opens to the countries along the Silk Road Economic Belt. However, there is no attractive high quality tourist attraction in the area, and there has never been a destination-type tourism center. As a result, the area is unable to play the various effects of tourism effectively. Zazulin Alexander, from Liuxing Street, Yining city, collected more than 1000 accordions from China and foreign countries by his personal strength, established an accordion museum, which is popular in China and foreign countries, and becomes the highlights of Ili's cultural industry. This paper takes accordion as an example and rely on "the Belt and Road" international tourism cooperation mechanism. Through the "rejuvenating Xinjiang through tourism" strategy, and the strategy of intelligent Tourism and integration of culture and tourism, the strategy of international tourism cooperation and innovation, and all-for-one tourism strategy, it is available to comprehensively promote the integration and development of accordion culture and museum industry and Liuxing Street tourism area in Yining city. Finally, it is also necessary to build the Liuxing Street, a state-level historical and cultural block into a national $4 \mathrm{~A}$ tourist attraction, to promote Yining becoming a tourism destination city.
\end{abstract}

Keywords-Ili; accordion culture and tourism integration;

*Fund: The National Social Science Fund Project of China "Study on the International tourism Cooperation mode of Grassland Culture between China and Kazakhstan under the Guidance of Shanghai Cooperation Organization"(12BJY129); Humanities and Social sciences Fund Project of the Ministry of Education "A Study on 'One road' and 'One belt' International Tourism Linkage Strategic Mode and Cooperation Mechanism between South and West" (17YJA790046); Open Social Science Fund Project of Research Center for Cooperative Development between Xinjiang and Neighboring Countries of Yili Normal University "Research on the Construction and Function of China and Central Asia's Grassland Culture International Tourism Circle under the Background of 'the Belt and Road' Initiative (2016ZBGJZD001) and "Research on the Development Path of Xinjiang Tourism Distributing Center Oriented to 'the Belt and Road' (2017ZBGJZD001).
Liuxing Street

\section{INTRODUCTION}

Tourism distribution centers can be roughly divided into two categories: one is the channel-type tourism distribution center, which has no, or lack of scenic spots and the tourism destination function is incomplete. This kind of distribution center only plays the function of gathering and distributing tourists, and the decisive role is its geographical location, traffic conditions and tourism infrastructure. The other one is the destination-type tourism distribution center, which has both scenic spots and distribution functions. Yining city is a national tourist city, with the beautiful south-China-type scenery impression, rich culture and eco-tourism resources; it has attracted a large number of domestic and foreign tourists and gradually developed into an important tourism distribution center in the northwest frontier. However, as it has not reflected its advantage of cultural heritage and internationality, as well as the lack of scenic spots and rich tourism products in urban area, Yining city has long been a channel-type tourism distribution center and has not developed into a good tourism destination. Therefore, the social, economic, cultural and international exchanges and co-operation effects of tourism has not been taken effect. This paper takes Bayan art, the unique Russian accordion culture in Yining city as the starting point, and the integration and development of accordion culture and museum industry and the folk culture tourism area in Liuxing Street as the research object. It focuses on the structural reform of the supply side of the cultural tourism industry in Ili, to build Liuxing Street folk culture tourism area into a national 4A tourist attraction with good economic, social and ecological benefits and strong attraction. Implement the strategy of "rejuvenating Xinjiang through tourism" and create a strong tourism market to promote Ili to become an important destination-type tourism distribution center on the Silk Road Economic Belt. 


\section{RESEARCH STATUS}

Traditionally, Liuxing Street is a Russian ethnic community where accordion culture is handed down and spread. Among them, Zazulin Alexander' Accordion Museum is a representative of the accordion culture, which has attracted the attention and research of cultural tourism and academic circles at home and abroad. Seven references are collected from CNKI for entries like" Liuxing Street of Yining City", "Accordion Museum of Alexander" and "accordion culture of Ili". Wu Lang and Pan Yonggang (2012) took Liuxing Street in Yining city of Xinjiang as an example to discuss the importance, protection and development of historical blocks recording the changes of the times in the development of the city. They started with the current situation of Liuxing Street and put forward the concept of planning, protection and development. Qiu Limei, Wang Ce, and Cheng Yusong (2014) thought that there were some problems in Liuxing Street, such as unsystematic greening, single landscape environment, and simple public facilities. Therefore, it is essential to update the concept, update the design, unify the planning and layout, and improve the public facilities. Lin Jiajia (2015) analyzed Liuxing Street in her master's thesis "Research on the protection zoning of Liuxing Street in Yili from the perspective of place", obtained the frequency distribution of image cognition of local residents, tourists and community professionals based on the image perception of people. She also analyzed the problems, put forward the protection objectives and principles of Liuxing Street, and built a multilevel and multi-dimensional Liuxing Street overall protection strategy. Cao Xu (2015) started from the space form of streets and lanes of Liuxing Street, and studied the specific performance, form and cultural modality of the space of streets and lanes of Liuxing Street. The architectural features of Liuxing Street dwellings is summarized by Izmati Turhanjan (2019), and the research on Liuxing Street dwellings is carried out from the aspects of courtyard structure, color and plane layout.

Among the references, only one scholar studies "Ili accordion culture". Ma Xi (2012) studied the development and characteristics of Ili accordion music culture. Taking time as the axis, she systematically introduced the origin, development, characteristics and current situation of accordion education of Ili accordion culture. She pointed out that Ili has a variety of accordion instruments, a variety of accordion music genres and styles, a variety of accordion musical performance forms, and an existing style of accordion music surrounded by diversity.

Although some scholars mentioned Alexander and his accordion collection in the article, at present, the research on Alexander Accordion Museum has not been carried out, nor has it involved the integration and development of culture and tourism of accordion in Yining city. Therefore, the indepth and systematic study of this issue is not only the need of the practice of cultural tourism integration in Ili Prefecture and Yining city, but also the need of academic research on this issue.

\section{DEVElopMent StATUS OF ILI ACCORDION CUlture AND MUSEUM INDUSTRY}

"Russian Bayan art" refers to the combination of performance art, maintenance technology and accordion culture research of Russian Bayan accordion. In 19th century, a large number of Russian immigrants came to Xinjiang to settle down, and became Chinese citizens in the long-term production and life of Ili Prefecture. Most of the Russian immigrants settled in Liuxing Street. Along with the Russian immigrants, there were also Russian accordion culture and "Russian Bayan art". Bayan art is integrated with the accordion art of all nationalities in Ili and the musical instrument performance art of other nationalities, forming the Chinese "Bayan art of Russian nationality" with the national cultural characteristics of Ili in Xinjiang. Zazulin Alexander is a representative figure.

Alexander, a Russian citizen of China, was born in Yining, Xinjiang in 1958. He is proficient in Russian, Uygur, Kazak and Xibo language. He is the first folk accordion collector and artist in Ili, and he is the leader of the accordion culture and museum industry in Yining city as well. Besides, he is a member of the Accordion Society of the Xinjiang Musicians Association, the curator of the Alexander Accordion Museum, and the inheritor of the intangible cultural heritage project "Russian Bayan art", a Russian accordion player, an accordion maintenance technician and an artisan. Although he has not received special music education in middle or higher education, he has created dozens of accordion music successively with his love for Ili and pursuit of accordion culture. In the past 30 years, he has collected more than 1000 accordions with the income of repairing accordions, covering more than 66 brands in 14 countries in Europe, Asia and America, including China, Russia, Germany, Italy, South Korea, France, Britain, Ukraine, Belarus, Poland, etc. He runs the only accordion museum completely formed by private collection in Xinjiang and even in China. In addition, he has collected more than 5000 Chinese and foreign musical instruments and many household utensils, such as clocks and watches, radios, cameras, containers and other daily necessities, plowshares, wheels and production tools used by Ili people in Xinjiang decades before. Alexander has lived in the cultural atmosphere of Liuxing Street multi-ethnic residential area for 60 years. His accordion cultural characteristics not only inherit Russian Bayan art, but also integrate the cultural and artistic elements of Han, Uygur, Kazak, Tatar, Hui and other ethnic minorities, forming a unique Alexander accordion cultural characteristics. Over the past 30 years, with the unremitting pursuit, careful management and joint efforts of the whole family, Alexander Accordion Museum has grown from small to large, from unknown to well-known, both inside and outside the Ili Prefecture. With more and more visitors coming in, the museum plays an increasingly social role in promoting Ili folk culture, accordion culture and Liuxing Street culture. According to incomplete statistics, the Alexander Accordion Museum has received more than 10,800 visitors from 2013 to 2019.

In September 2018, Alexander and Yining Tourism Bureau have signed a cooperation agreement, after signing 
snack bar, Russian style Leba, shaq and black bread, maklik pizza, Wusun Kazak milk tea house, etc., forming a rich catering culture.

\section{d) Ethnic education}

The only school named after "Russia" was established in 1985. Because of the uniqueness of Russian school in Xinjiang, it has become the tourism resources of Russian culture and education in Liuxing Street.

\section{e) Museum}

There is a folk culture exhibition hall in Liuxing Street with a building area of $1212.74 \mathrm{~m}^{2}$. The first floor is folk culture exhibition hall, and the second floor is Alexander accordion collection hall. There is also a folk museum with Alexander's private accordions and other collections. Among them, there are 308 accordions, more than 5000 collections of various national musical instruments and historical production and living utensils.

\section{f) Religious culture}

There is a mosque built in 1949, a 667 square meter Russian Orthodox Church and a $20 \mathrm{mu}$ (1.334 hectares) Russian cemetery

\section{DEVELOPMENT STATUS OF FOLK TOURISM IN LIUXING STREET OF HISTORICAL AND CULTURE BLOCK}

\section{A. Overview of Liuxing Street in the Historical and Cultural Block}

Liuxing Street was built in the mid-1930s (1934-1936), and was named as a historical and cultural block in 2012. As the whole block is composed of three streets (Liguang Street, Worker Street and Saiyilamu Street), which are scattered from the central point to become six main streets, Ili locals have long established the term as "Liuxing Street".

Liuxing Street covers an area of 47 hectares, and now inhabits eight ethnic groups, including Han, Uygur, Kazak, Hui, Xibo, Tatar, Russian, Kirgiz, etc., with multi-ethnic symbiosis and cultural integration. There are 3813 people in 1198 households in Liuxing Street community. There are 3 enterprises and institutions, 1 school (middle school, primary school and kindergarten), 1 mosque, 130 believers and 479 commercial outlets.

\section{B. Types and Uniqueness of Folk Culture Tourism Resources}

\section{1) Types of folk culture tourism resources}

\section{a) Characteristic national architecture}

Main representatives are Russian style attic, high platform and wooden house porch; Uyghur style dome arch, semi bow window lattice, woodcarving, stone carving floating plate and various iron porch.

\section{b) Folk culture}

Russian Bayan art and tap dance, Uyghur advocacy music, Uyghur Pinball art and other folk culture form the multi-ethnic cultural elements of Ili that can be enjoyed and participated in.

\section{c) Catering culture}

There are many featured restaurants in Liuxing Street, such as Russian small wooden house dining bar, old Kazak

\section{2) The uniqueness of folk culture tourism resources}

The characteristics of folk culture tourism resources can be summarized as diversity, the integration of historical blocks and folk culture, and the unique cultural ecology of Russian accordion, which can be interpreted in detail from the "five national uniqueness". First, it is the only historical and cultural block with the architectural style of Liuxing Street in China; Second, with the Russian national culture as the main feature, the folk culture of Han, Uygur, Kazak, Tatar, Hui and other ethnic groups has been integrated and developed for a long time in a block, which is the only one in China. Third, the "world accordion Museum" (including non-accordion Collection) is the only one in China with more than one thousand collections founded by Russian collectors. Fourth, it is the only elementary education nationality school named after "Russia" in China. Fifthly, the only high-level folk "Ili national unity accordion band" is composed of eight ethnic accordion performers, including Russian, Tatar, Xibo, Han, Uygur, Kazak, Hui and Kirgiz.

In 2009, Yining municipal Party committee and government invested 44.4 million Yuan to renovate Liuxing Street on the basis of protecting the overall style and features of Liuxing Street. In the process of renovation, the original style and features of the street were protected to the greatest extent. On February 1, 2010, after Liuxing Street was named as a historical and cultural block by the people's Government of the autonomous region, Yining municipal government has increased its investment in the infrastructure reconstruction of Liuxing Street, striving to build a livable, tourist and business friendly tourist block with strong national customs and profound historical culture. In 2018, $7 \mathrm{~km}$ of curbstone replacement was completed, 28,000 square meters of road was oiled and 3500 square meters of sidewalk pavement were completed. In 2019, the upgrading and reconstruction project of Liuxing Street will promote rapidly, and the underground comprehensive pipe gallery, clean energy 
technological content and foresight in infrastructure construction need to be improved.

implement. Centering on the development goal of "Silk Road Flower City, colorful Yining", the exterior walls of the block courtyards are painted and decorated, and the streets planted with fruit trees and canals. By planting fruit trees blooming in different seasons to extend the flowering period of the area, visitors can feel the ecological beauty of the historical block anytime and anywhere, and taste all kinds of special fruits. At present, the $16 \mathrm{~km}$ water system transformation has completed. After the completion of the whole project, the life scene of Ili old street of Liuxing Street will reappear.

In the past decade, the city's tourism infrastructure construction project has made remarkable achievements; especially the fully and rapidly promoting transformation project of Liuxing Street. The government encourages the conditioned courtyards to be transformed into homestays with Ili characteristics. At present, there are three homestays opened in Liuxing Street, and more than 10 are under investment. However, from the perspective of mining characteristics and the integration depth of culture and tourism, the integration of Ili's characteristic culture and tourism is not enough in breadth, depth and brightness, especially in accordion culture and tourism.

\section{THE DEFICIENCIES OF YINING CITY ACCORDION CULTURE AND TOURISM INTEGRATION DEVELOPMENT}

\section{A. The Problems in Opening Mind and Renewing Ideas}

Culture and museum tourist resources are the soul of the historical and cultural district of Liuxing Street to develop its tourism. However, this concept is not well understood by local people or local government. It has been a long time that Alexander accordion collection, repair and performance art are well-known at home and abroad. Actually, the resources of Alexander accordion collection repair and performance art is an advantage of Liuxing Street, however this advantage hasn't been fully taken by the Cultural Tourism Department of the local government at the beginning. In addition, the development of tourism industry is relatively slow, the investment in the early stage is insufficient, and the development of tourism attractions aiming at cultural and museum tourism is too late and too slow.

\section{B. Problems in Infrastructure Construction}

Liuxing Street is located between Jiefang Road, Jiangsu Road and North Ring Road, which is in a relatively tight area. The infrastructure reconstruction and construction should first meet the needs of tourists, and have an appropriate forecast on the number of tourists and the diversion path. For example, the demand for food, accommodation, travel, shopping and entertainment, the demand for parking space and management of self-driving travel; Secondly, it should reflect certain scientific and technological skills, such as the real-time display the number of tourists and guide tourists to flow reasonably. Thirdly, the design of tourism public transportation route, the connection of the transport nodes, the tourist transport signs, the tourist attractions signs and the tourist toilets construction should have both forward-looking and regional characteristics. However, from the perspective of current planning and construction, the scientific and

\section{Problems in the Development and Marketing of Culture and Tourism Industry}

Input "Liuxing Street" in Baidu, a total of 47700 relevant results is displayed. However, there are only more than 100 articles that directly introduce the tourism resources and products of Liuxing street, and the rest are basically local news, bidding announcement, visitor blog, etc. There are few advertising about Liuxing Street by either official or tourism enterprises, but the visitors' blogs all introduce the Alexander Accordion Museum. This indicates that: the government and tourism enterprises have not organized and targeted the publicity of Alexander Accordion Museum. The integration degree of culture and tourism represented by Alexander Accordion Museum is not enough, and it is not attractive to tourism enterprises.

\section{Problems in Policy and Management}

Recently, the relevant departments of Yining city and Alexander have established the Accordion Collection Museum, but there are still some problems in management. For example, the contract needs to be detailed, the division of rights and responsibilities needs to be more reasonable, the distribution mechanism is not detailed, and the management system needs to be optimized. These problems directly affect the enthusiasm of participants.

\section{THE STRATEGY OF YINING CITY ACCORDION CULTURE AND TOURISM INTEGRATION DEVELOPMENT}

\section{A. The Strategy of Rejuvenating Xinjiang by Tourism}

The government work report of the National People's Congress of Xinjiang Uygur Autonomous Region in March 2018 and the Tourism Development Conference of Xinjiang Uygur Autonomous Region in 2018 put forward the strategy of "rejuvenating Xinjiang through tourism" to comprehensively promote the development of tourism in Xinjiang. Seize the great opportunity of implementing the strategy of "rejuvenating Xinjiang by tourism", and make full use of the policies issued by the autonomous region for the implementation of the strategy. By seeking cultural tourism resources, combine tourism elements with the creation of A-level national scenic spot perfectly. Highlight the Liuxing Street accordion culture and ethnic culture and historical district, design unique and distinct IP, build a perfect industrial chain, and finally achieve the function of tourist destination-type distribution center in Yining city.

\section{B. International Tourism Cooperation and Innovation Strategy}

International tourism cooperation and innovation strategy refers to taking the accordion culture internationalization as the soul and bond, relying on the "the belt and road" international tourism cooperation mechanism to develop tourism market and innovate scenic spots and tourism products. This operating mode includes amending the management system and operation mode, and creating a national tourist attraction by combining single building with overall promotion. 
Street. Chinese Horticulture Abstracts, 2014, pp.114-115+128. (in Chinese)

[6] Cao Xu, The Study on street space form of Yining Liu Xing Jie ,Xin Jiang.Modern Decoration(Theory), 2015,pp.54. (in Chinese)

[7] Ma Qian, The development and characteristics of Yili Accordion Music Culture .Journal of Xinjiang University of the Arts, 2012,vol.X,pp.32-35. (in Chinese)

[8] General Office of the State Council, Guidance on Promoting the Development of All-for-one Tourism. Avalliable at http://www.gov.cn/zhengce/content/.2018-03-22 .(in Chinese)

[9] Hu Yuelong ,Douqun, A New Concept of Development for All-forone Tourism. China Tourism News.2015-10-26.(in Chinese)

[10] Li Jinzao, A Bright Future for All-for-one Tourism. Avalliable at https://www.mct.gov.cn/.2016-02-07 .(in Chinese)

[11] Xiong Gaizhi, Content and Future of Smart Tourism Construction. Information China,2013,pp.93-95. (in Chinese)
General plan for all-for-one tourism strategy refers to take a certain area as a complete tourist destination and take tourism there as the dominant leading industry. Through unified planning and integration of resources to promote the integration of various industries and fields, enhance the new functions of tourism development, and promote the overall development of other industries, and meet the needs of tourism consumption better. The strategy could be a kind of comprehensive operation mode to build a new type of tourism area, which is coordinated and integrated with other industries. In order to develop Yining city tourism and Liuxing Street folk culture tourism zone, it is necessary to seize the great opportunity and the right situation of the development of all-for-one tourism in Ili prefecture. Full advantage of conditions and superiorities of all industries in Ili Prefecture should be taken to build all-for-one tourism, and work together to promote the development of tourism in Yining city and Liuxing Street folk culture tourism area.

\section{CONCLUSION}

The strategy of "rejuvenating Xinjiang through tourism", and "rejuvenating Ili Prefecture through tourism", as well as social stability and rich tourism resources are the guarantee to develop tourism in Ili and in Xinjiang. As long as Yining city could explore its profound historical culture and integrate the distinctive cultural products with tourism in height and depth, meanwhile, optimize the infrastructure and rely on the advantageous geographical location along "the belt and road", it will be able to build a distinctive destination tourist distribution center in the era of the great development of tourism.

\section{REFERENCES}

[1] Wang Kunxin, Evaluation and Development of Tourism Resources. Beijing,Tsinghua University Press. 2010. (in Chinese)

[2] Ma Yaofeng,Yan Yan,Wei Fengqun, Tourism Planning. Beijing: China Renmin University Press. 2011. (in Chinese)

[3] Lin Jiajia, Research on the Protection Division of Liuxing Street in Yili City from the Perspective of Place. Mianyang: Southwest University. 2015. (in Chinese)

[4] Wulang, Pan Yonggang, Retaining the City in Modern Urban Life Strategies to perspective and develop Liu Xing Jie historic distractive in Yinin.Journal of Xi'an University of Architecture and Technology, 2012,vol.XXXI,pp. 54-59.(in Chinese)

[5] Qiu Limei,Wangce, and Cheng Yusong, The Renovation of Xinjiang Historical and cultural block - A Case Study from Yining Liuxing 